\title{
THE ROLE OF CURING PERIOD ON THE ENGINEERING CHARACTERISTICS OF A CEMENT-STABILIZED SOIL
}

Antonia Athanasopoulou, Associate Professor, Democritus University of Thrace, anatha@ civil.duth.gr

\begin{abstract}
Very often, pavements constructed in an economical manner or matching surface elevations of adjacent lanes cannot be designed for the soil conditions of the existing subgrade. Therefore, there is a need to stabilize the soil with an appropriate chemical substance in order to increase its strength to a satisfactory level. For the enhancement of subgrade soil strength characteristics, lime and cement are the most commonly used stabilizers. An experimental program was directed to the evaluation of a clayey soil and its mixtures with different cement contents performing tests on the index properties, the moisture-density relation, the unconfined compressive strength, and linear shrinkage. There is a definite improvement in strength. The time interval used to cure the prepared specimens affected positively both strength and plasticity features of the mixtures. A comparison with mixtures of the same soil with lime has been made, because of the wide use of lime in clay soil stabilization projects.
\end{abstract}

Keywords: cement, clay, curing time, lime, soil stabilization, strength

\section{INTRODUCTION}

If the subgrade in pavement constructions consists of clayey soils, then severe pavement distress may arise due to low subgrade support values, as well as due to volume changes induced by moisture. While lime's ability to stabilize plastic clays is well known, highly effective clay stabilization is also provided by Portland cement, generally with the advantage of higher strength gain. Calcium-based stabilizers such as lime and cement modify the soil properties through pozzolanic reaction, flocculation and agglomeration, and cation exchange. Moreover, cement provides hydration products, which increase the strength of the subgrade materials and enhance the permanence of the treatment. Several factors affect stabilization, including stabilizer test procedures, dosage effects to soil properties, mixing, compaction, and gradation and pulverization.

Research works reviewed by Prusinski and Bhattacharja [1] indicate that cement is at least as effective as lime in stabilizing soils having moderate to high 
plasticity values (plasticity index, PI, up to 50). Generally, the engineering properties of clays are significantly enhanced, with only small amounts of stabilizer.

Mixtures of soil with cement can undergo shrinkage in drying periods, like summer. The shrinkage state of the material, as well as any subsequent cracking, depends on soil type, cement and water contents, the degree of compaction, and on time and conditions of curing. When cement stabilized soils are used as pavement subgrade, it is important to minimize shrinkage cracking and obtain a uniform layer. In order to reduce the shrinkage effects, the surface of the laid material should be kept moist for longer periods and its moisture content slightly below optimum. The effect of cement and lime addition in different proportions on the shrinkage properties of soil specimens has also been extensively studied by Gharib et al. [2].

Prakash et al. [3] investigated the effects of lime added to a montmorillonite soil and the curing time on the compaction characteristics as well as on the liquid and shrinkage limits of the soil. For a given lime content, they have found that the liquid and shrinkage limits increased with curing time, while the optimum moisture and maximum dry density definitely decreased. The aforementioned authors have tried to highlight physical and chemical factors involved in the alteration of soil's technical characteristics. Aiming to study the effect of lime, natural pozzolana, or a combination of such materials on the geotechnical features of cohesive soils, Harichane et al. [4] tested mixes with additive contents of $0 \%$ to $8 \%$ and $0 \%$ to $20 \%$ for lime and pozzolana, respectively. Compaction and shear tests were performed after curing periods of 1, 7, 28 and 90 days. In later ages, both soils have been improved in both internal friction angle and cohesion.

The effects of influential factors, such as water content, cement content, curing time, and compaction energy on the engineering characteristics of cement-stabilized soils have been comprehensively researched [5, 6]. Suganya and Sivapullaiah [7] tried to reveal the influence of cement as binder and mechanisms of interaction leading to strengthening of clay, based on parameters like clay water/cement ratio, initial water content of soil and curing period analyzing the unconfined compressive strength (UCS) of the stabilized soil. The strength of samples that had been cured for 14 days was higher than that of samples cured for seven days. Syed et al. [8] reported that the unconfined compressive strength of stabilized soils increased with the addition of cement with respect to curing days. At longer curing periods, strength gain is dominated 
by the effect of pozzolanic reaction, while at shorter curing periods by the effect of density [9].

Water content, cement content, and curing time have been investigated by Horpibulsuk et al. [10] in an effort to analyze the performance of cementstabilized silty clay. It was estimated that with time, the large pores are filled with cementitious products, increasing the small pore volume, and decreasing the total pore volume. Thus, a strength development over time is imparted.

The role of curing time and compaction energy on the strength development of cemented clay has been illustrated by Horpibulsuk et al. [10]. It was shown that, at a particular curing time, the strength depends on the compaction energy. As the compaction energy increases, the maximum strength increases and the water content at maximum strength decreases. For the same compaction energy, the strength curves were similar (almost symmetrical around 1.2 optimum water content) for all curing times.

The engineering behavior of cement admixed clay soils has been discussed in detail by Suebsuk et al. [11, 12]. Horpibulsuk et al. [13] presented the strength and compression characteristics of lightweight cemented clays with varying swelling potential (non- to high). The clay's characteristics were governed by the voids volume/cement volume (v/c) ratio. The cement volume mainly affected the levels of bonding (inter-particle forces).

Portland cement is a heterogeneous material containing di- and tricalcium silicates $(\mathrm{C} 2 \mathrm{~S}, \mathrm{C} 3 \mathrm{~S})$, tri-calcium aluminate $(\mathrm{C} 3 \mathrm{~A})$ and tetracalcium aluminoferrite (C4AF). When it comes in contact with the pore water of the soil, calcium silicates and aluminates composing the Portland cement are hydrated and form the cementing compounds of calcium-silicate-hydrate and calciumaluminate-hydrate, as well as excess calcium hydroxide (lime) deposited as a separate phase. Due to the formation of cementitious material and calcium hydroxide, Portland cement could be a successful stabilizer for both fine-grained and granular soils, as well as aggregates.

If sufficient cement is present, then the hydration products induce cementation between the soil particles. When cement is added to a soil, the liquid limit, plastic limit and the potential for volume change of soils are usually reduced, while there is an increase in the shrinkage and shear strength behavior. The reduced plasticity is a result of the partial or complete destruction or even the alteration of any clay minerals. Increased compressive and tensile strength of the cement treated soil is provided by cementitious reactions (primary and secondary) in the soil-cement matrix. Because both lime and cement contain enough calcium to be consumed, the same pozzolanic reactions cause the soil's 
strength gain when either cement or lime is used. What is different is the origin of the required silica. With lime stabilization to obtain the necessary silica the clay particles have to break down, an action which is not needed with cement stabilization. Cement stabilization, unlike lime stabilization, is rather independent of the soil characteristics, the only requirement being the soil to contain enough water for the hydration process to begin.

In cement stabilization, carbonation can also take place similarly to lime stabilization. Cement exposed to air reacts with the atmospheric carbon dioxide producing a practically insoluble calcium carbonate. As with the use of lime, in order for premature carbonation of cement -through exposure to air- to be avoided, proper handling methods and advanced construction procedures should be ensured.

Cement stabilization of soils presents many advantages as it is easily available, cost effective and very durable. Soil cement is also quite weather resistant, is fairly strong, and reduces the swelling characteristics of the soil. Due to cement interaction with the silt and clay fractions of the soil, their affinity for water is reduced. The main shortcomings of cement stabilization are (a) the crack formation (b) the extra labor required, (c) its harmfulness for the environment, and (d) the quantity of water needed for the hydration to be completed and to ensure sufficient workability for the mixture.

\section{DESCRIPTION OF MATERIALS AND TESTING METHODOLOGY}

Soil samples have been taken from a 1 meter deep excavation located near the Via Egnatia road in the northern part of Evros District, Greece. The dark black colored clayey soils are very common in the area since they constitute deposits of the Ardas and Evros Rivers. They have resulted from the weathering of volcanic rocks (andesites, rhyolites, etc.) found in the rivers' basin. Serious damages and serviceability loss had arisen in the surface layer of the pavement a few years after it's opening to traffic. Alligator form and longitudinal cracks could be attributed to the weak support of the road's body on soils with very low bearing capacity.

Portland cement used in the laboratory testing was of Type I/45 available in the market ("Titan" Ltd. Thessaloniki, Northern Greece). Lime was a typical commercial hydrated calcitic lime with a high $(65.25 \%)$ calcium oxide content.

The water used in soil-cement should be relatively clean and free from harmful amounts of alkalies, acid, or organic matter. Drinkable water is satisfactory. The quantities of water and Portland cement to be added, as well as 
ROMANIAN JOURNAL

OF TRANSPORT INFRASTRUCTURE

the density, to which the mixture must be compacted, are determined from tests. In order to properly produce a soil-cement mix, enough water must be assured for two purposes to be served: first, helping to obtain maximum compaction through the lubrication of soil grains and second, hydrating the cement which in turn hardens and binds the soil into a solid mass.

The soil samples had been carried to the laboratory where they were airdried and pulverized. The soil's grain size distribution was determined using a combination of standard sieves and the hydrometer test. The gradation curve is depicted in Fig. 1. The soil belongs to group A-7-6(20) according to the AASHTO classification system. When the U.S. Unified Soil Classification System (USCS) is employed, the soil is characterized as high plasticity clay, $\mathrm{CH}$. The suitability of soils in these classification categories is fair to poor for the construction of road pavements.

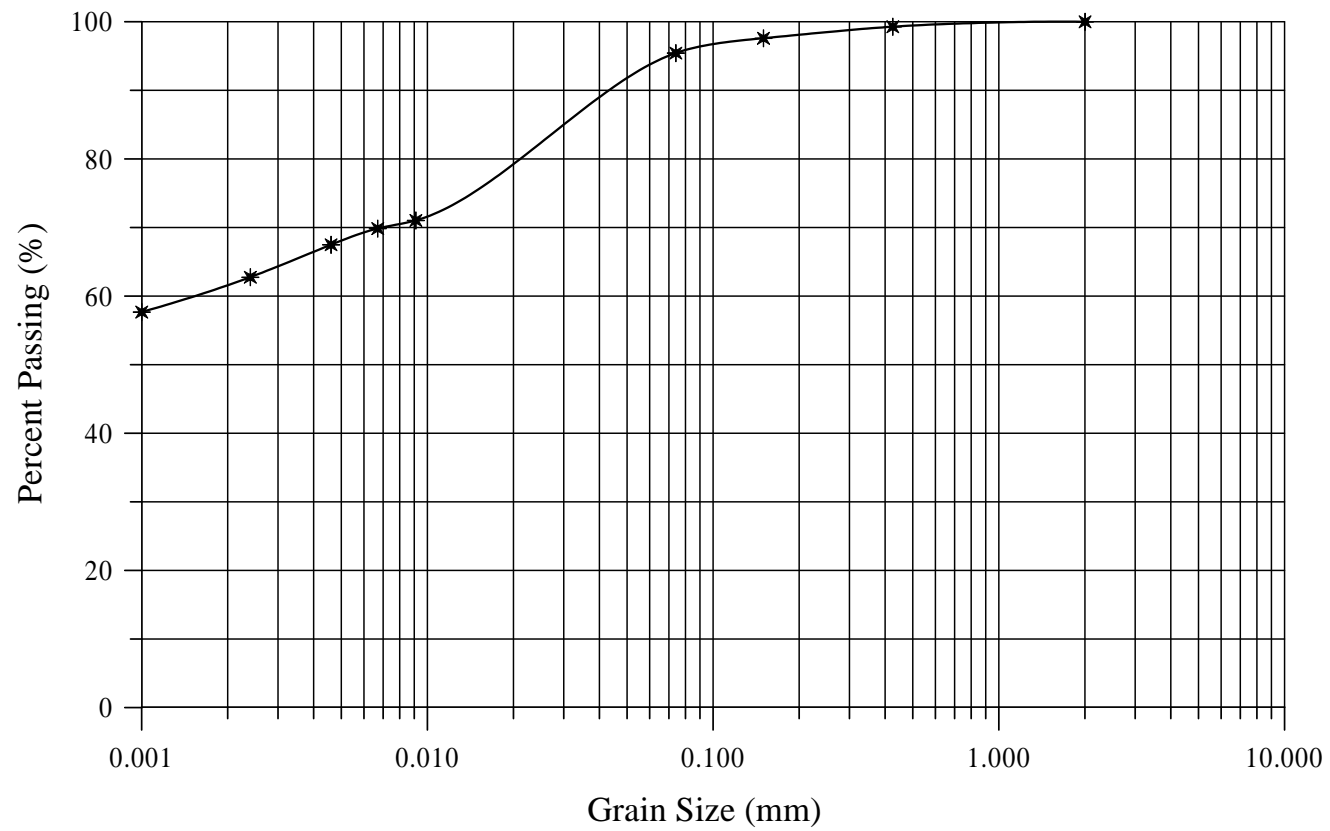

Figure 1. Grain size distribution of the soil tested

When cement was added to soil samples at various rates, the engineering properties had changed. In order to assess these alterations, a series of laboratory tests had been carried out. They included the determination of index properties, the moisture content-dry density relationship and the unconfined compressive strength test.

Portions of the soil fraction passing the No. 40 sieve were thoroughly mixed with various amounts of cement. The Atterberg limits of soil and the soilcement mixes were determined using the procedure described in ASTM D 4318. 
Tests were carried out to determine the compaction properties of the clay upon stabilization with varying amounts of cement. The optimum moisture content and the maximum dry density of the soil and all combinations of soil and additives had been determined using the Proctor standard compaction procedure. Prior to the Proctor testing procedure, all samples remained to cure in plastic bags for 24 hours.

Specimens for the determination of unconfined compressive strength were prepared at the corresponding optimum moisture content and maximum dry density for each soil-stabilizer mixture, using static loading. Mixing of the materials to form specimens continued until the mixture was thoroughly blended and a high degree of homogeneity had been achieved. It is thought that through such a procedure more consistent results could be obtained. The compacted specimens were numbered and stored in a humid room and cured for 7 days, 28 days and 90 days time periods, under controlled moisture conditions (relative humidity 95\%) and temperatures ranging between $21^{\circ} \mathrm{C}$ and $25^{\circ} \mathrm{C}$.

Three groups of specimens have been prepared corresponding to the selected curing times. For the soil sample and each soil-stabilizer mixture three cylindrical specimens 50x100mm (diameter $\mathrm{x}$ height) were formed and fractured following the procedure ASTM D 2166. The mean value of fracture limits represented the UCS value.

Because lime is the broader used stabilizing agent in clay soils used as pavement foundation, all the above mentioned procedure had been repeated with various lime contents, to have a reasonable comparison basis.

\section{RESULTS AND DISCUSSION}

Among the problems arisen with the stabilization of clay soils is their mineralogical composition meaning that some of them is more easily stabilized [14]. The X-Ray diffraction analysis has shown that the clay contained a mixture of clay minerals with montmorillonite being the dominant constituent in the clay fraction. In the radiogram kaolinite, illite and calcite are also appearing.

The main non-clay minerals determined in the soil sample were quartz and in smaller quantities calcite $\left(29.30^{\circ}, 3.06 \AA\right)$ and albite $\left(28.01^{\circ}, 3.18 \AA\right)$. The diagnostic reflection of quartz was $3.33 \AA$ with secondary reflections at $4.25 \AA$, $2.45 \AA, 3.77 \AA$, and $2.28 \AA$. The clay minerals detected were montmorillonite (reflection at $14.23 \AA$ ) muscovite $(9.93 \AA$ ) and a small quantity of kaolinite with diagnostic reflection in $11.6^{\circ}, 7.62 \AA$. 
Since many of the composite hydrated silica, alumina, or alumino-silica compounds have common or almost inseparable peak positions, a constituent in high percent may shade the existence of small quantities of another compound. The results of the analysis of the soil sample and various soil-lime mixtures are given in radiogram form in Fig. 2. The soil-lime mixtures have been cured for 28 and 90 days.

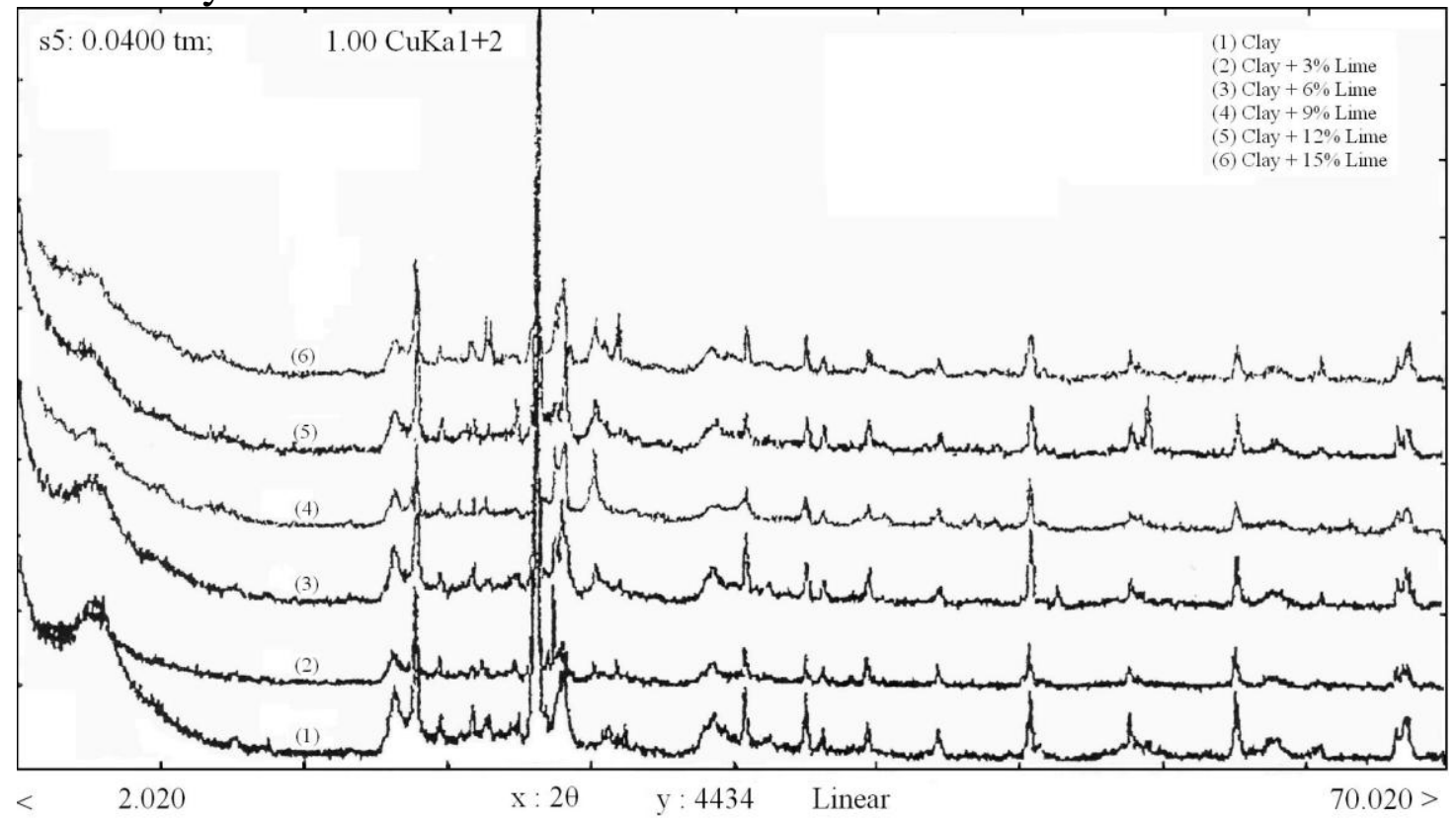

Figure 2. Radiograms of soil sample and soil-lime mixtures

The effect of cement content on the Atterberg limits for curing times of 30 minutes, one hour, and 24 hours, is shown in Table 1.

Table 1. Influence of curing time on Atterberg limits for mixtures with different cement contents

\begin{tabular}{cccccccccc}
\hline Cement & \multicolumn{10}{c}{ Curing time } \\
\cline { 2 - 11 } content & \multicolumn{3}{c}{30 minutes } & \multicolumn{10}{c}{60 minutes } & \multicolumn{3}{c}{24 hours } \\
\cline { 2 - 10 }$(\%)$ & LL & PL & PI & LL & PL & PI & LL & PL & PI \\
0 & $(\%)$ & $(\%)$ & $(\%)$ & $(\%)$ & $(\%)$ & $(\%)$ & $(\%)$ & $(\%)$ & $(\%)$ \\
\hline 2 & 78 & 33 & 45 & 72 & 31 & 41 & 73 & 33 & 40 \\
4 & 71 & 33 & 38 & 72 & 35 & 37 & 60 & 33 & 27 \\
6 & 67 & 39 & 28 & 58 & 33 & 25 & 60 & 37 & 23 \\
8 & 62 & 37 & 25 & 67 & 45 & 22 & 66 & 45 & 21 \\
10 & 55 & 32 & 23 & 65 & 44 & 21 & 72 & 53 & 19 \\
12 & 60 & 38 & 22 & 62 & 41 & 21 & 76 & 57 & 19 \\
\hline
\end{tabular}


With increasing cement percentages in the soil-stabilizer mixes the liquid limit (LL) generally reduced and the plastic limit (PL) increased, particularly with the smaller additive contents. An increased plasticity limit shows that the stabilized material has the capacity to maintain its stability when the moisture content increases.

The plasticity index systematically reduced reaching medium plasticity values. With the addition of $8 \%$ cement the reduction in PI is almost $50 \%$. The reduced PI values are mainly attributed to the reduction of liquid limit.

Liquid limit variations did not show a discernible pattern in the soilcement mixtures, fluctuating rather fuzzily with different curing periods. In the prolonged curing time of 24 hours the plasticity limit for cement contents larger than $2 \%$ showed increased values in comparison to both 30 minutes and one hour curing state.

For all additive contents, one hour curing yielded values of plasticity limit greater than those in 30 minutes curing.

Figure 3 shows the effect of curing time on the plasticity characteristics of the clayey soil after its treatment with cement and lime.

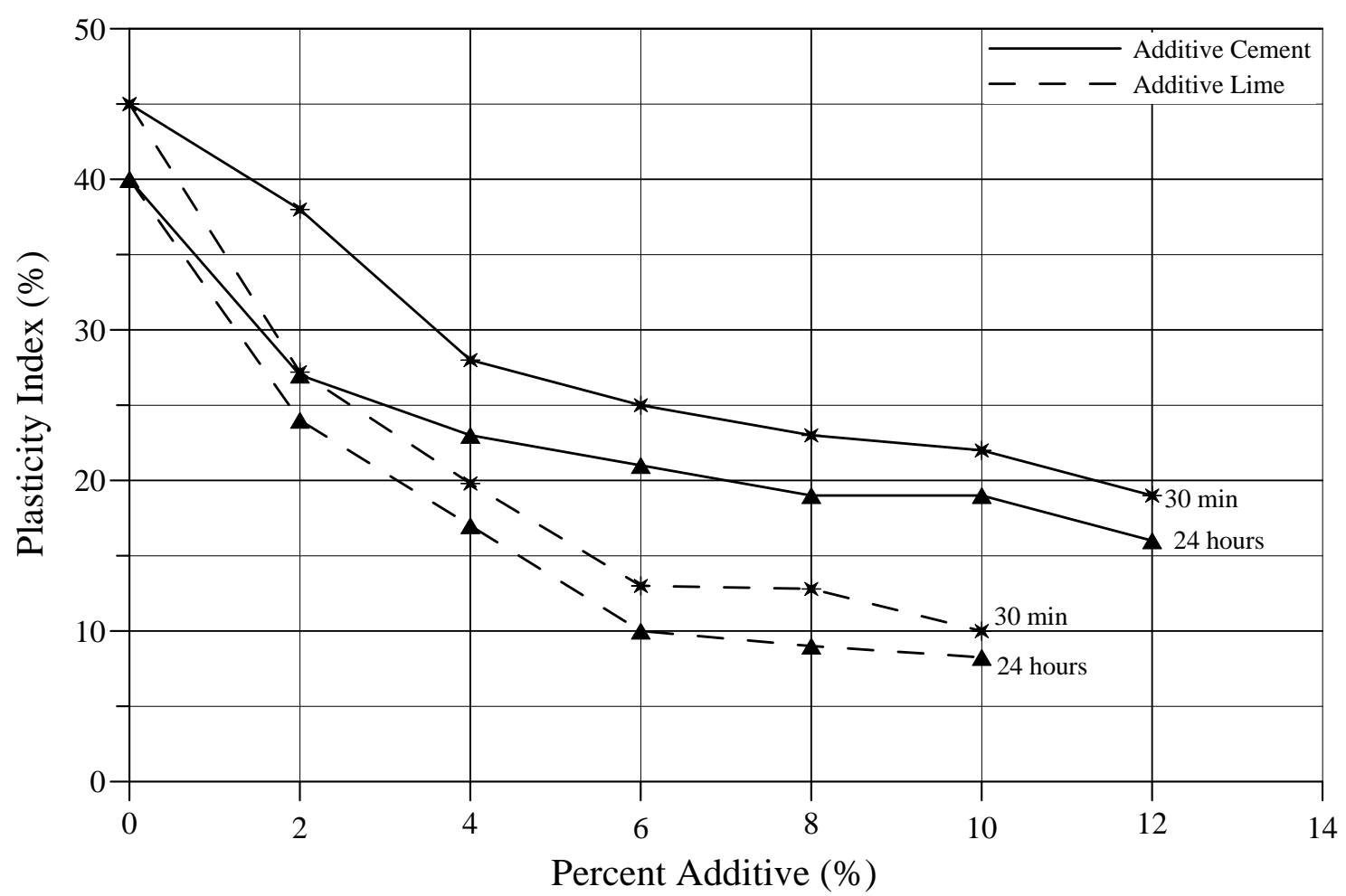

Figure 3. Influence of additive content on the Plasticity Index for different curing times 
ROMANIAN JOURNAL

OF TRANSPORT INFRASTRUCTURE

Curing all mixtures with additives for a half an hour period led to higher PI values than the corresponding mixtures cured for 24 hours. The time of curing plays a significant role as the reduction in the plasticity index is higher after 24 hours of curing. The plasticity index is reduced with a quick rate up to $6 \%$ lime and $8 \%$ cement following a slower reduction rate for greater additive contents. The PI decrease rate of lime stabilized specimens was more pronounced than the rate of PI reduction of soil-cement mixtures. When a curing period of 24 hours was employed, the stabilization product fell in the low plasticity region $(\mathrm{PI}<20)$. The curing of soil-lime mixtures favors pozzolanic reactions of alumina/silica and lime, forming various types of cementing compounds which cover and bind the clay platelets in larger agglomerations.

The linear shrinkage reduced with the addition of cement, resulting in significant enhancement of the material swelling characteristics (Fig. 4).

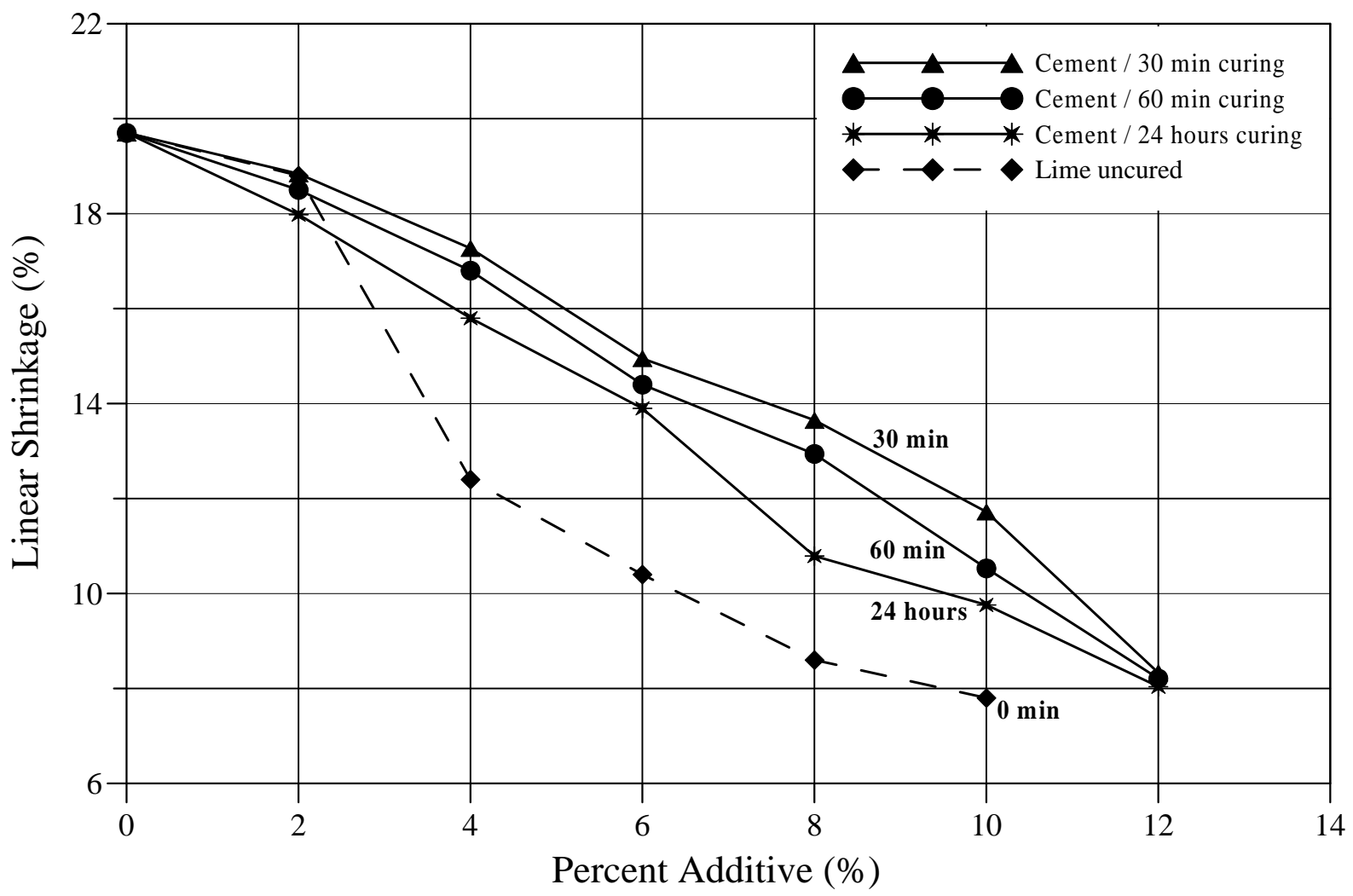

Figure 4. Percent additive versus linear shrinkage for different curing times

With the addition of $12 \%$ cement, there existed a reduction of over $58 \%$ in the percentage of linear shrinkage compared with that of the untreated clay. The same trend has been noticed for all curing times. Increased curing times led to lower percentage of linear shrinkage. The higher benefit $(21 \%)$ had been noted 
in the case of $8 \%$ cement content and curing times 30 minutes and 24 hours. A cement content of $12 \%$ seems to bring no further improvement, since any more stabilizing material added to the soil will not lower the percentage of linear shrinkage. The reduction of the linear shrinkage percentage after mixing the soil with $2 \%$ lime is relatively small (reduction of $5.1 \%$ in comparison with the untreated soil). When $4 \%$ lime was used, the largest variation had been noted (reduction of the initial value by $37.1 \%$ ). The reduced swelling characteristics of the soil tested could be attributed to the lowered trend for moisture retention by the calcium saturated clay, as well as to the formation of a cementitious matrix that resists volume changes due to lime or cement addition. Further reduction with curing time occurred because of the random structure mobilized by the coarser agglomerations formed during the pozzolanic reaction.

The value of unconfined compressive strength is quite low, typical of the clayey soils, and it does not satisfy the suitability criteria for subgrade soils in road construction practice. When various cement or lime quantities had been added to the soil, its strength characteristics had been improved. For the strength improvement, a central role had been played by the curing time.

In Fig. 5 the strength variation curves of the soil sample are presented as a function of the percentages of cement and lime used for the preparation of unconfined compressive strength specimens. The curves drawn are related to curing times of 7, 28 and 90 days.

Upon the addition of $3 \%$ cement, the unconfined compressive strength increased. The compressive strength continued to increase after each increment of added cement. This trend was nearly linear for curing periods of 7 and 28 days. The rate of increase was more pronounced for cement contents higher than $6 \%$, especially for the specimens tested after 90 days of curing. Adding to soil $9 \%$ cement by dry weight caused a compressive strength tripled the soil strength after 7 days curing, while seven-fold strength had been recorded after 28 and 90 days curing. For $19 \%$ cement content in the mix, the strength after 90 days curing was 15.57 times higher than the strength value of the untreated soil.

With the addition of Portland cement to the cohesive soil tested, agglomerations with the small grains had been created. When interconnected, these agglomerations created a cellular structure with material particles in the voids without cement. This strong skeleton increased the soil strength and decreased soil's plasticity.

The admixture of lime to the soil brought about an enhancement in UCS. The optimum lime content ranged about $8 \%$ to $10 \%$ by dry weight of the 
ROMANIAN JOURNAL

OF TRANSPORT INFRASTRUCTURE

physical soil. When excess lime (more than 10\%) had been added, it acted as a filler material lowering the strength values.

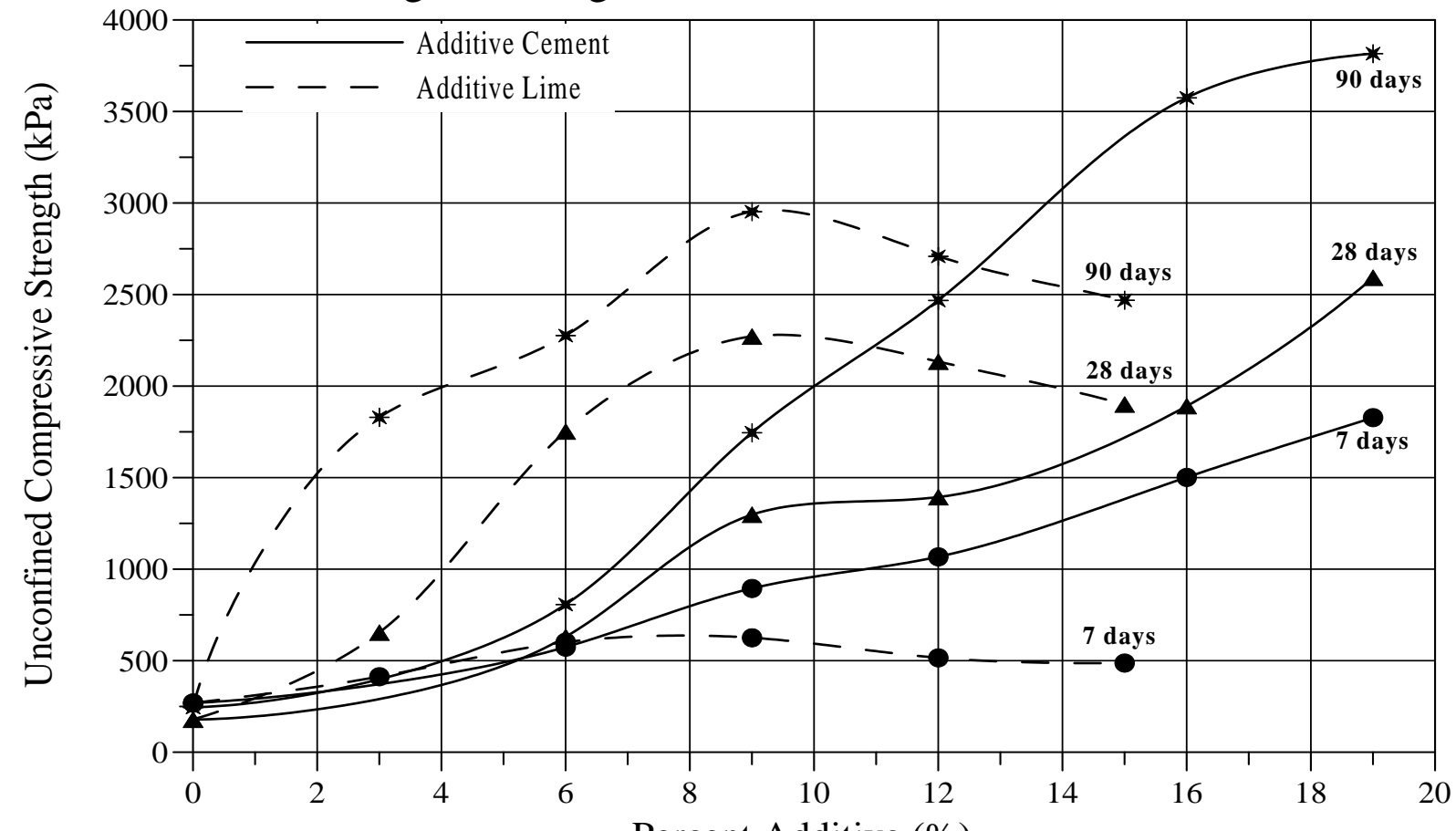

Percent Additive (\%)

Figure 5. Effect of additives' content on unconfined compressive strength for different curing times

The strength of the soil had been enhanced through the formation of cementitious products generated through the interaction between lime and soil silica and soil alumina in pozzolanic reactions taking place in the course of this process.

The compressive strength of lime stabilized specimens was higher to that of cement-soil mixtures up to $15 \%$ additive when the samples were cured for 28 days and up to $12 \%$ when the samples were left to cure for 90 days. The unconfined compressive strength of the samples with $9 \%$ lime was almost twofold (1.7 times) that of the samples with the same cement percentage, for 28 and 90 days curing.

For cement contents of $6 \%$ and $12 \%$, the increase in strength with curing time was almost linear (Fig. 6). In most cases, the rate of strength increase was less pronounced in specimens cured more than 28 days. Calcium ions liberated from cement hydrolysis upon reaction with hydrous silica and alumina form insoluble compounds. These reaction products harden as the time passes in the curing period causing the stabilization of the soil. 
ROMANIAN JOURNAL

OF TRANSPORT INFRASTRUCTURE

Antonia Athanasopoulou

The role of curing period on the engineering characteristics of a cement-stabilized soil

The curing time length significantly affected the increase in unconfined compressive strength of the soil-lime mixtures, as it is shown in Fig. 7.

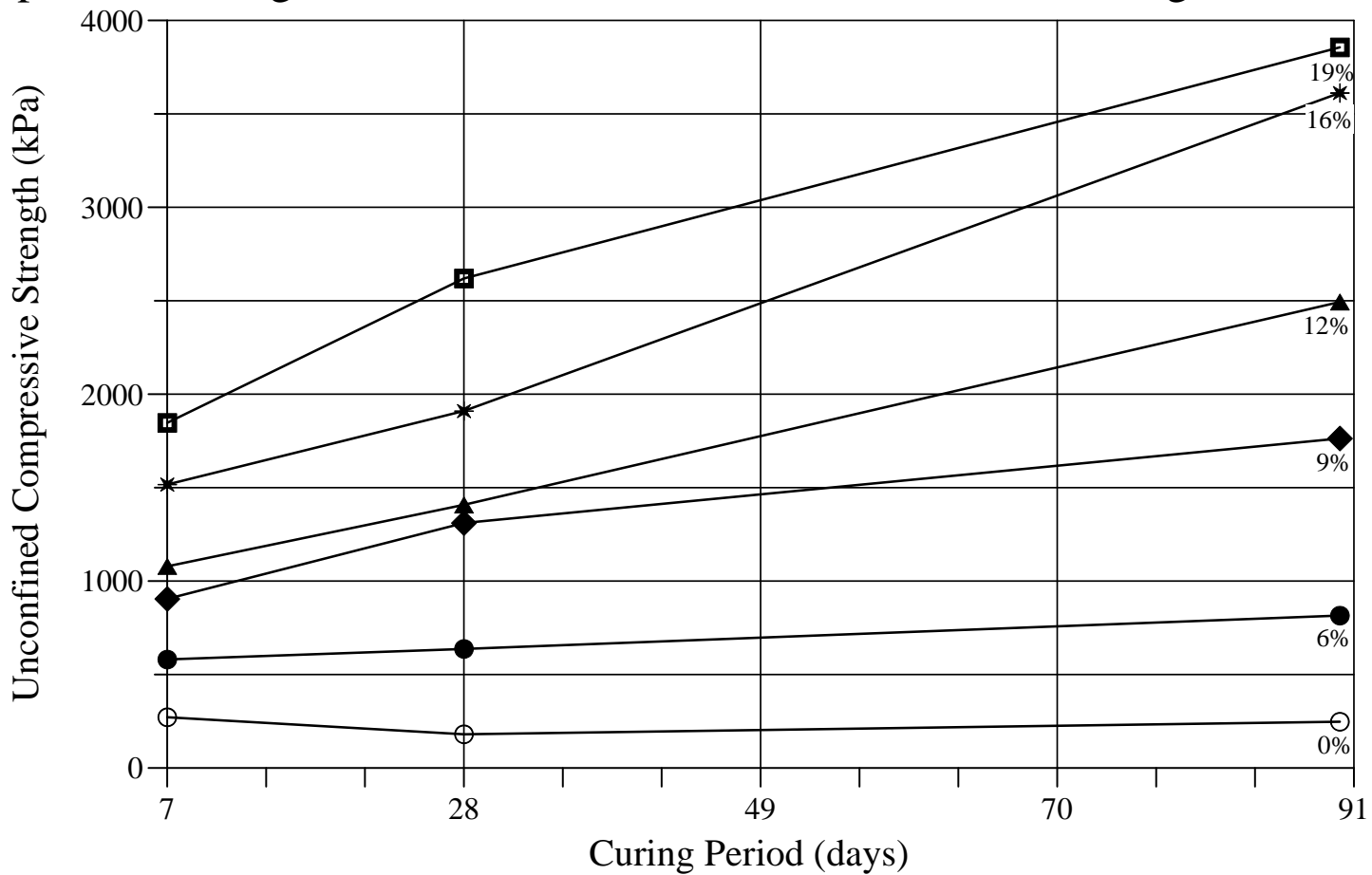

Figure 6. Influence of curing time on UCS for various cement contents

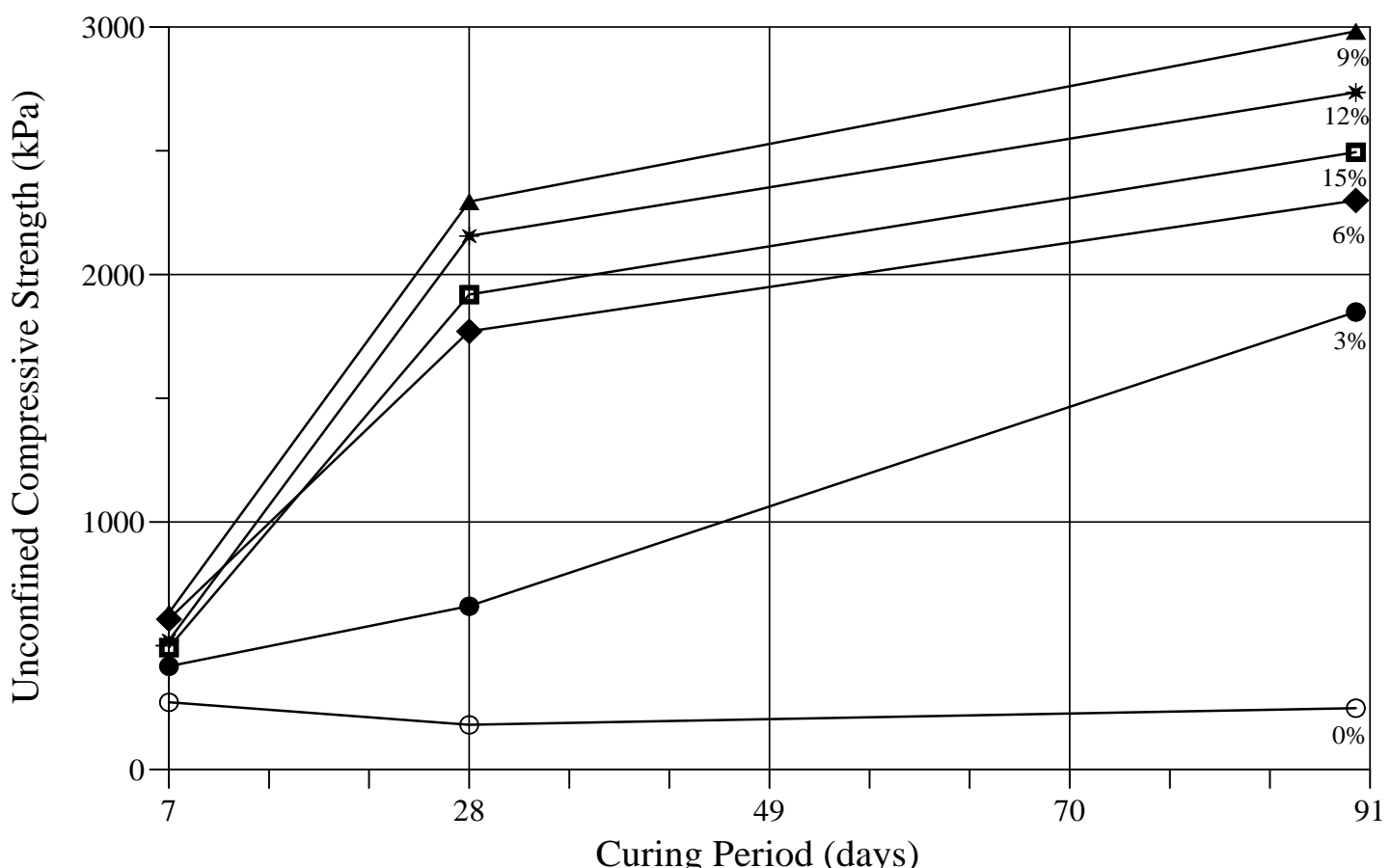

Figure 7. Influence of curing time on UCS for various lime contents 
In the early maturing phase, after 7 days of storing under controlled moisture and temperature conditions, the strength of all soil-lime mixtures was definitely higher than that of the untreated sample. The larger increase had been produced in the case of 9\% (by dry weight of soil) added lime; compared to the untreated soil UCS, the strength ratio was $3.65,9.19$ and 11.11 when the mixes were cured for 7, 28 and 90 days, respectively.

The change in time-strength curves gradient is of particular importance. The course of hardening process is characterized by a high initial increase in strength, followed by a period of gradual, yet with a lower rate, reaction. Such behavior could be attributed to the fact that the formation of reaction products close to clay particles impedes the penetration of additional lime. The relationships between curing time and UCS are not always linear, since strengths after a long curing period are arisen due to the development of crystals, rather than the immediate lime reaction $[15,16]$.

\section{Conclusions}

Laboratory results have shown that calcium-based stabilizers -cement and lime- modified clay soil properties through pozzolanic reaction, flocculation and agglomeration, and cation exchange.

The admixture of cement and lime to the soil tested has led to significant changes in Atterberg limits and linear shrinkage. The electric charges around the clay particles are altered, changing the conditions of their coverage with water. As a result, the particles attract each other and form agglomerations. Prolonged curing of the mixtures led to coarser particles formation and to a more flocculated arrangement of the particles.

Increasing the lime content in soil-additive mixtures caused an increase of the unconfined strength up to a point and then the strength-additive content curve started to decline. With the addition of cement there has been no such point of change.

At smaller percentages, lime addition resulted to higher strength values than cement addition, while for cement contents higher than 15\% (curing for 28 days) and $12 \%$ (curing for 90 days) the gain in strength of the treated soil was higher. Cement provided hydration products, which increased the strength of the soil materials and enhanced the permanence of the treatment.

For both additives, an increase in curing period resulted to an increase in strength. The ultimate strength of the soil after its improvement is adequate for the soil to be used as subgrade or embankment material in main roads, or even as base in some secondary roads. 
Cement stabilization of the clay soil tested had effects similar to those produced when lime was used as additive. It is suggested that cement stabilisation develops from cementitious links between the soil particles and calcium silicate and aluminate hydration products. Addition of cement to clay soil reduced the liquid limit, plasticity index and increased the shrinkage limit as well as the compressive strength.

The effect of lime stabilisation on the strength and microstructure of clay soils should also be examined in view of not only the curing period length, but in view of temperature changes during the curing.

\section{REFERENCES}

[1]. J.R. PRUSINSKI, S. BHATTACHARJA: "Effectiveness of Portland cement and lime in stabilizing clay soils", Transportation Research Record, 1652, pp. 1-13, 1999.

[2]. M. GHARIB, H. SABA, A. BARAZESH: "The effect of additives on clay soil properties using cement and lime", International Journal of Basic Sciences \& Applied Research, vol. 1(3), pp. 66-78, 2012.

[3]. K. PRAKASH, A. SRIDHARAN, S.M. RAO: "Lime addition and curing effects on the index and compaction characteristics of a montmorillonitic soil", Geotechnical Engineering, vol. 20(1), pp. 39-47, 1989.

[4]. K. HARICHANE, M. GHRICI, S. KENAI: "Effect of curing time on shear strength of cohesive soils stabilized with combination of lime and natural pozzolana", International Journal of Civil Engineering, vol. 9(2), pp. 90-96, 2011.

[5]. N.C. CONSOLI, G.V. ROTTA, P.D.M. PRIETTO: "Influence of curing under stress on the triaxial response of cemented soil", Géotechnique, vol. 50(1), pp. 99-105, 2000.

[6]. F.H.M. PORTELINHA, D.C. LIMA, M.P.F. FONTES, C.A.B. CARVALHO: "Modification of a lateritic soil with lime and cement: An economical alternative for flexible pavement layers", Soils and Rocks, São Paulo, vol. 35(1), pp. 51-63, 2012.

[7]. K. SUGANYA, P.V. SIVAPULLAIAH: "Mechanisms of binder interactions and their role in strengthening Kuttanad clay", Proceedings of the $18^{\text {th }}$ International Conference on Soil Mechanics and Geotechnical Engineering, Paris, pp. 429-432, 2013.

[8]. I.M. SYED, G.K. FUSELIER, P.E.M. HEWITT: "Innovation in cement stabilization of airfield subgrades", Proceedings of FAA Worldwide Airport Technology Transfer Conference. Atlantic City, New Jersey, USA, pp. 6-8, 2007. 
ROMANIAN JOURNAL

\section{OF TRANSPORT INFRASTRUCTURE}

[9]. S.M. PRASANNA KUMAR: "Cementitious compounds formation using pozzolans and their effect on stabilization of soils of varying engineering properties", International Conference on Environment Science and Engineering, vol. 8, pp. 212215, 2011.

[10]. S. HORPIBULSUK, R. RACHAN, A. CHINKULKIJNIWAT, Y. RAKSACHON, A. SUDDEEPONG: "Analysis of strength development in cement-stabilized silty clay from microstructural considerations", Construction and Building Materials, vol. 24(10), pp. 2011-2021, 2010.

[11]. J. SUEBSUK, S. HORPIBULSUK, M.D. LIU: "Modified Structured Cam Clay: a constitutive model for destructured, naturally structured and artificially structured clays", Computers and Geotechnics, vol. 37, pp. 956-968, 2010.

[12]. J. SUEBSUK, S. HORPIBULSUK, M.D. LIU: “A critical state model for overconsolidated structured clays", Computers and Geotechnics, vol. 38, pp. 648-658, 2011.

[13]. S. HORPIBULSUK, A. SUDDEEPONG, A. CHINKULKIJNIWAT, M.D. LIU: Strength and compressibility of lightweight cemented clays. Applied Clay Science, vol. 69, pp. 11-21, 2012.

[14]. P. SOLANKI, M. ZAMAN: Microstructural and mineralogical characterization of clay stabilized using calcium-based stabilizers, Scanning Electron Microscopy, Dr. Viacheslav Kazmiruk (Ed.), 2012.

[15]. A. ATHANASOPOULOU, G. KOLLAROS: "Use of additives to improve the engineering properties of swelling soils in Thrace, Northern Greece", $5^{\text {th }}$ International Conference on Computational Materials Characterization, WIT Press, pp. 327-338, 2011.

[16]. D.I. BOARDMAN, S. GLENDINNING, C.D.F. ROGERS: "Development of stabilisation and solidification in lime-clay mixes", Géotechnique, vol. 51(6), pp. 533-543, 2001. 